\title{
Science Meets Philosophy: Metaphysical Gap \& Bilateral Brain
}

\author{
Plato's Cave Allegory Explains the Metaphysical Gap \\ Separating Reality From Human Experience \\ Presages Quantum Physics Particle-Wave Duality \\ Kant's Two Senses Confirmed by Bilateral Human Brain \\ Phenomenal-Right \& Noumenal-Left Hemispheres \\ Our Free-Floating Bilateral Double Ego in Both Cerebral Hemispheres \\ Left Brain: Saint Teresa of Avila’s Interior Castle \\ Hermann G. W. Burchard \\ Oklahoma State University, Stillwater OK, USA
}

\begin{abstract}
The essay brings a summation of human efforts seeking to understand our existence. Plato and Kant \& cognitive science complete reduction of philosophy to a neural mechanism, evolved along elementary Darwinian principles. Plato in his famous Cave Allegory explains that between reality and our experience of it there exists a great chasm, a metaphysical gap, fully confirmed through particle-wave duality of quantum physics. Kant found that we have two kinds of perception, two senses: By the spatial outer sense we perceive phenomena, objects in space. Our temporal inner sense lets us perceive our inner state, noumena. Kant's two senses are fully confirmed through bilateral brain duality of cognitive science. The bilateral brain serves inner, temporal sense, logic \& noumena in the left hemisphere. The right brain half is for the outer, spatial sense, geometry \& phenomena. We form a whole system, a bilateral interior cosmos, a kind of world model, expressing what may lie beyond the metaphysical gap. In the right brain we build a phenomenal cosmos, to resemble the outer environment. In the brain's left hemisphere a noumenal cosmos, a model of our private world including Saint Teresa of Avila's castillo interior. The cosmos is regularly updated with novel sense data integrated into our memory banks. This was recognized early by Helmholtz (1860s). Our lives, health \& well-being depend on us keeping our interior cosmos in good order. This used to be seen as saving one's precious soul from perdition. While we endeavour to keep our phenomenal cosmos neat \& orderly by protecting the environment from harm, our noumenal cosmos to be livable requires us to engage in ethical conduct. This bilateral cosmos is responsible for our common sense judgment power, that we depend on for being able to lead a good \& benign life. The 200 million neurons of BA10 in the prefrontal lobe have global access to the interior cosmos, \& apply massive feedback to identify environmental conditions rapidly. The global access also gives conscious presence of the individual to itself, all that is present in the interior cosmos, for total freedom of action. In the left brain private ego, we are guarded by faith in divine mercy, \& guided to choose the best course of action, able to survive under the most adverse conditions. For this, we receive directions from the Holy Ghost in Saint Teresa's castillo interior.
\end{abstract}

Hermann G. W. Burchard, Prof. Emer., Dept. of Mathematics, Oklahoma State University, Stillwater OK 74078, USA. 
Keywords: Kant's inner \& outer senses, orderly inner self \& chaotic outer environment, brain laterality, interior cosmos, metaphysical gap

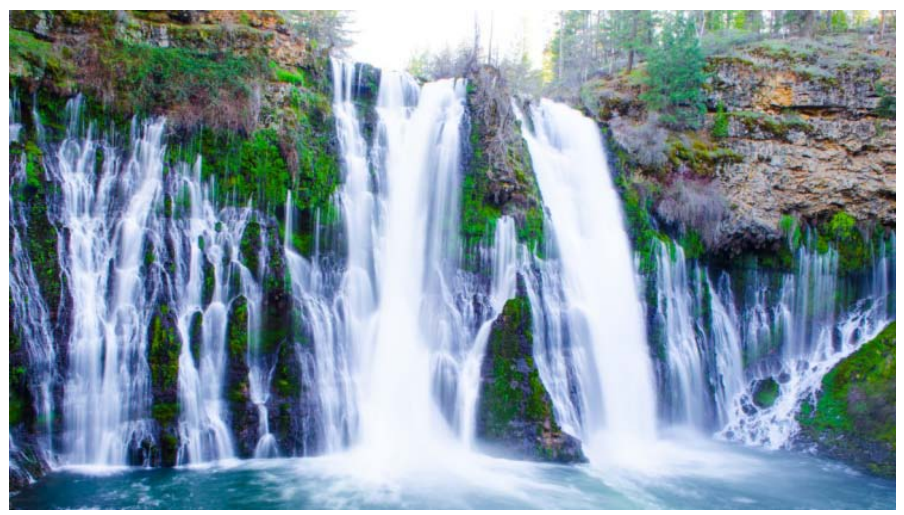

Figure 1. Burney Falls, Modoc Plateau, Shasta County, California.

\section{Dedication}

To my wonderful children, Paul, Julja \& Sonja, in memory of their sister Anna, likewise honoring their great artist mother.

We celebrate the beautiful world that we live in given to us by our eternal Father in Heaven who lives far above the tent of the sky that he has stretched over our lives, mercifully.

\section{Preamble}

A necessity has become apparent to preface this essay on where philosophy stands, to forestall, if possible, readers doubts in or even contempt for theory \& facts presented. At this time in my life at 85 years of age and maintaining my alertness \& sound mind in ways \& by means that are some of the very subject matter of this work, trouble arises from imperfections of the paper itself in the way it is written, in an aphoristic or even poetic style, hints of my aspirations as the picaresque folk hero. While I do cite a few references, it is hoped that my prior work will interest readers sufficiently for a glance, first perusing my 93 page article of 2005 in Foundations of Science, rough draft for C. F. von Weizsaecker's 90th birthday June 2002, which he gave to someone else to read because of his age. I sent it to the FOS editor November 2002. ${ }^{1}$ There was a delay until July 2005 when Springer acquired publisher Kluwer \& moved production to Chennai. Another essay in the same journal followed 2011, wherein I propose my definitive theory of consciousness. Quoting the abstract:

Impressions, energy radiated by phenomena in the momentary environmental scene, enter sensory neurons, creating in afferent nerves a data stream. Following Kant, by our inner sense the mind perceives its own thoughts as it ties together sense data into an internalized scene. The mind, residing in the brain, logically a Language Machine, processes and stores items as coded grammatical entities. Kantian synthetic unity in the linguistic brain is able to deliver our experience of the scene as we appear to see it. Uniquely, the brain records its own history, synthesizing a Movie-in-the-Brain, called the Noumenal Cosmos. Attempting thereby to represent the actual Universe, this makes for a sovereign brain that governs itself. The brain is domicile of an Ego, with its selfhood at stake at all times. Yet, it can know itself only by its actions, in which it appears as an actor in its own movie. Phenomena enter garbled, as confused apparitions, and must be put in good form using top-down feedback control by Ego, so that each movie frame makes rational sense within the overall context of

\footnotetext{
${ }^{1}$ It was plagiarized Nov 2002 by Hauser, Chomsky, Fitch. Later, Fitch himself, on Mark Liberman's Language Log, termed it "that infamous paper.” Hauser was fired 2010 from Harvard for drylabing. Fitch never returned my friendly email.
} 
the Noumenal Cosmos. A stack of frames is processed typically in $40 \mathrm{~Hz}$ rhythm with $300 \mathrm{~ms}$ process time each, for about 12 in the stack at any time. Successive neural centers are processing the stack in the brain assembly line, based on data from increasingly global receptive fields. Ego stitches together the movie frames, but only the top frame is in consciousness for $25 \mathrm{~ms}$. The top frame contains the whole scene where the Ego makes an appearance as the actor that imposes Kantian synthetic unity on the scene, merely an assembly of grammatical texts, in a system-internal coded process language, fitting the scene into the Noumenal Cosmos. But Ego observes Ego only to the extent permitted by the objectivity rule, only what it does and thinks, not its true face. From the Noumenal Cosmos, the Ego receives grammatical messages in the internal sense code. They are integrated into a whole in the reaction of the Ego to the momentary scene.

Self-taught except for sitting in C. F. von Weizsaecker's Logic seminar for several years, and being to his home a few times where his gracious wife brought us tea and cake to our garden table, beside hearing his auditorium lectures with 2,000 other enthusiasts, I lack the rigor of course work in a philosophy department although thinking of myself as a philosopher since age 14. Then, one day on the way home from school, I thought by myself that I didn't have to be afraid anymore. Living under the Nazi dictatorship as a boy with wavy hair, slightly olive skin \& a semitic cut to the face had been a ten year ordeal for me and my parents.

\section{Introduction}

This essay brings a summation of millennial human efforts seeking to understand our existence as sentient beings. Two giants, Plato and Kant, combined with today's cognitive science, allow us to complete our reduction of philosophy to the story of a neural mechanism, which though highly complex, has evolved along elementary Darwinian principles giving to animals, including us humans, a chance of opportunistic survival within the grand biological ecosystem of The Little Blue Planet Earth.

\section{Science Meets Philosophy: Plato’s Metaphysical Gap \& Quantum Physics}

Synopsis: Human experience is separated from reality by a chasm partially bridged by language. Not until the discoveries of quantum physics did humanity have to acknowledge the full meaning of Plato's Cave Allegory.

Plato, in his famous Cave Allegory, gave to humanity the enduring formula for how we get to know things, the basic process by which we filter the data that enter into our biological system as we see on the wall before our eyes shadows of images carried behind our backs cast by the light of an unknowable fire burning somewhere in the cave's recesses (Plato, 375 BC).

As Plato explains metaphorically, between reality and our experience of it there exists a grand chasm, a metaphysical gap, by which we are separated from understanding the true nature of our world, something we can believe he had learned from his teacher Socrates.

Plato made this discovery, a scientific fact of the first order, thinking \& working 2,400 years ago during the prescientific age.

Ours is a questionable and indeed fragile way to know the world, but fortunately we can try \& gain an understanding of issues arising, the gap being described lucidly by interpretation of Plato's cave, that has been handed down to us through the centuries \& millennia, unlike so many other writings of the ancients.

When quantum physics was discovered at the beginning of the 20th century, featuring the new concept of particle-wave duality, philosophers in vain tried to talk it away, not accepting consciously \& failing to recognize the other-worldy character of quantum effects, not focussing on, not realizing fully the extra-experiential significance, of the newly observed effects. 
Plato's metaphysical gap is fully confirmed through the wave-particle duality of quantum physics. In quantum physics we learn that reality consists in energy being transported in the form of waves, but deposited as energy quanta like colliding particles.

Louis de Broglie actually discovered waves belonging to electrons before Erwin Schrödinger created wave mechanics, influencing him.

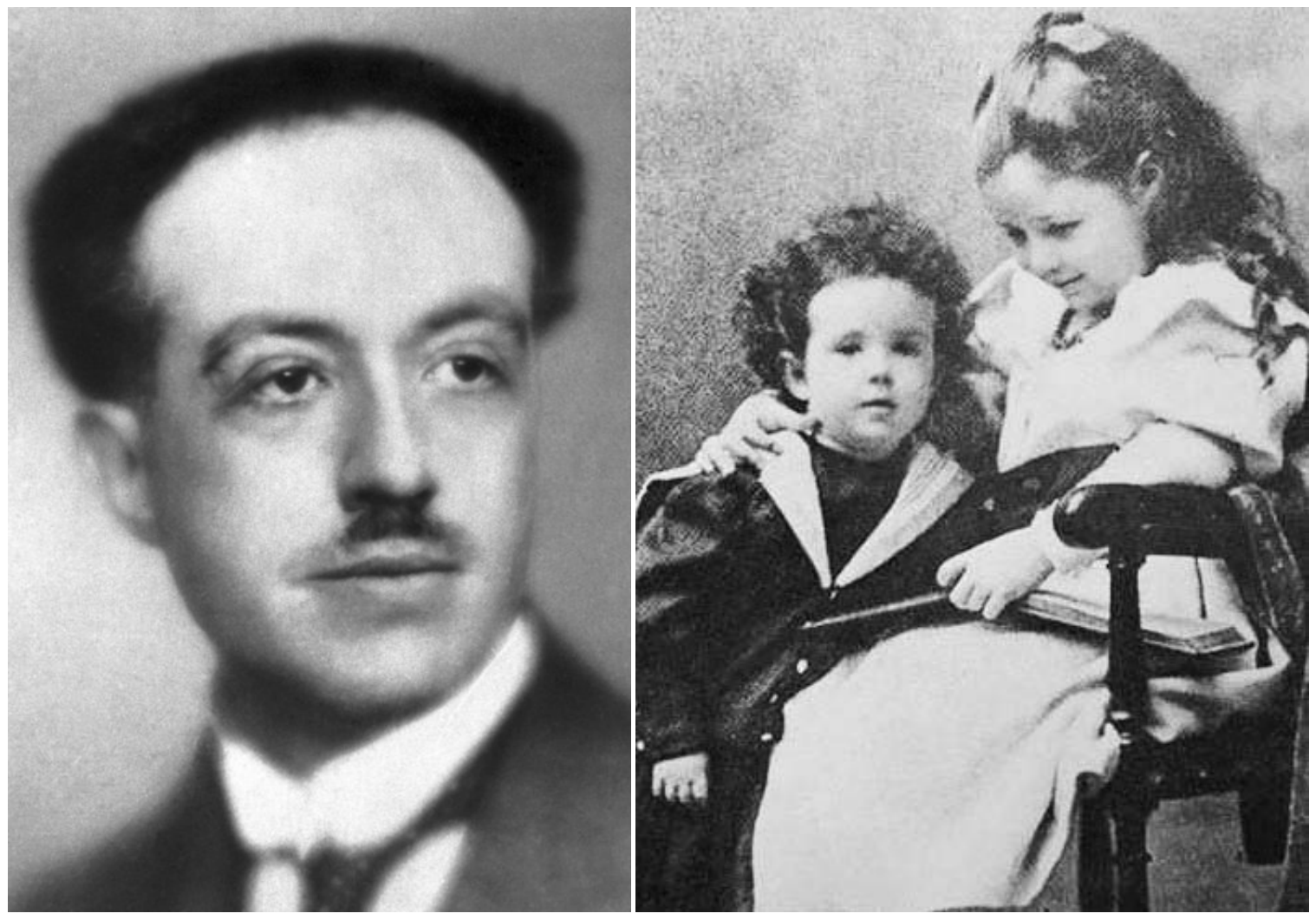

Figure 2. Louis de Broglie \& his sister Pauline.

While this is physical reality, our inborn or native neural mechanisms, by which we experience the world cannot accommodate the fact. The shadow on the wall bears scant similarity to the unknown form carried above the parapet.

Thinkers were disturbed deeply and tried to ignore the new empirical findings. New philosophical schools sprang up, developing their existential, linguistic, \& utilitarian doctrines. They might have recalled Plato’s Cave instead \& invoked his metaphysical gap, explaining to themselves that reality lies beyond our ken, on the opposite shore of an unfathomable abyss. The intellectuals of the age neglected to pay homage to the ancient philosopher for his power of abstract thought.

Our slow recognition of Plato's metaphysical gap as an explanation of quantum duality demonstrates the origin by opportunistic evolution of the human brain's neural scheme. Science Meets Philosophy...!!

Plato himself made an enormous step of progress in old age, a long story: ${ }^{2}$ He gave a lecture in Athens "On the Good," in the Piraeus Harbor suburb. People came in droves to hear him, but he presented an abstruse

${ }^{2}$ Bennett B. Gilbert (2012). Plato’s Lost Lecture “'On the Good.” Normative Ethics and Intellectual History. MS Thesis, Reed College. 
theory trying to put philosophy into mathematical figures \& formulas. Folks right away started to leave the lecture hall in disgust and dismay, and shortly only five of his closest students were left. Seeing the error of his ways, he thereafter had some key insights and came up with a new dialogue, Philebus, his last. As Jacques Derrida has alerted us (The Double Session, 1972), Plato had early insights that we would consider to belong to cognitive science. In the Philebus, he recognized that our mind works like a book written by an author (left brain), and like pictures painted by a painter (right brain).

It also comes as no surprise that we find our neural mechanisms to be inadequate beyond our everyday human experience...

As we will see below, language forms a bridge over the metaphysical gap.

Wigner's quantum foam may give an inkling of what lies on the other side. As we now understand it, a high frequency random quantum field oscillation, it consists in an assembly of Feynman diagrams to be averaged over by Gaussian probability Wiener processes under the Feynman path integral.

\section{Science Meets Philosophy: Immanuel Kant Anticipates the Asymmetric Functionality of the Bilateral Brain}

Synopsis: Immanuel Kant's 18th century desktop discovery of two senses, inner, temporal logical vs. outer, spatial geometric, today is confirmed by cognitive science of the bilateral brain. The left hemisphere harbors the inner sense, while the spatial outer sense has its domicile in the right brain.

Immanuel Kant found that we have two kinds of perception, two senses, for two types of objects. By the spatial geometric outer sense we perceive objects in space, while our temporal logical inner sense lets us perceive our inner state.

In parallel, he also reformulated Plato's dualism of a sensible and another intelligible world in terms of mental phenomena \& noumena, where in contrast to Plato's realism, he conceives these as mental objects—-thus establishing his idealism.

By virtue of discoveries of cognitive neuroscience in recent decades, Kant's two senses, part of his transcendental metaphysics, are fully confirmed as localizable neuroanatomically in the two bilateral brain hemispheres.

The right brain half is for conveying outer sense spatial geometric phenomena. The left hemisphere is devoted to the inner sense temporal logic of noumena.

In the right brain, we build our phenomenal cosmos, an interior model of the external world, an organized record of phenomena \& events as they develop around us in the immediate environment that the phenomenal cosmos is meant to resemble. It also includes associations \& other ancillary data that may aid the animal with survival.

In the brain's left hemisphere a noumenal cosmos models our private world. It includes Saint Teresa of Avila's castillo interior.

The noumenal cosmos in the left brain harbors our memories, theoretical constructs, plans, dreams, private thoughts \& hopes (Kant, 1781 A, 1787 B; Burchard, 2019, 2020). We re-make the external mess into a lovely, if virtual, bilateral cosmos, a man-made fantasy of an orderly neat interior world model. But it's not reality, let's be honest (Brook, 2006; Burchard, 2005, 2011,..., 2020; Kant, 1790; Rorty, 1979). We have the very recent results in cognitive science by Iglói, Doeller, Berthoz, Rondi-Reig, and Burgess (2010), “... the 
hippocampus predicts and supports navigation via sequential representations in the left hippocampus and allocentric spatial representations in the right hippocampus."

Remaining puzzles could be resolved by giving more play to the Kantian inner/outer sense characterization. E.g., the following quote refers to boundaries of imagined scenes, and therefore clearly falls under the left-lateral inner sense: "The left lateralization of the boundary effect is apparently at odds with neuropsychological evidence that visuospatial processing in the medial temporal lobe is right lateralized” (Bird, Capponi, King, Doeller, \& Burgess, 2010, p. 11694). It is noteworthy that the authors appear to expect right-lateral activation, wrongly, ignoring that the imagined scene is perceived by Kant's inner sense.

Neuroscientific studies of the right/left brain opposition go back decades and in the second half of the preceding century were advanced by Brenda Milner, McGill University, and her students Mary Lou Smith and Patricia Frisk (Milner, 1971; Smith \& Milner, 1989; Frisk \& Milner, 1990), drawing early attention and a growing literature on mental defects occasioned by lateralized brain trauma or surgical excision (as for relief of epileptic seizures).

Brenda Milner has been awarded the 2014 Kavli Prize in Neuroscience by the Norwegian Academy for her pioneering work on brain laterality, but a vast literature is emerging of new details by many distinguished workers. This sensational connection of 18th century desk work composed with a goose quill \& 21st century neuro-lab work still largely remains off-side in our splintered academic set-up.

An exciting, I think sensational, aspect is that the 18th century philosopher Immanuel Kant had been able to predict the function of the brain halves, and accordingly we can refer to the Kantian noumenal left brain \& the phenomenal right hemisphere.

We also depend on Kant's lasting contribution, his reformulation of Platonic sensible \& intelligible world dualism, in form of the distinction of entities as either phenomenal or noumenal, which today's cognitive science covers fully through the bilateral right/left brain functional division of labor.

However, continuing to rely on the Cave Allegory as our axiom, Plato's metaphysical gap stands between reality \& our experience, obstructing direct access to such life data. This way have been conditions throughout the paleontological history of the tribe, compelling Darwinian evolution of an information system as a part of

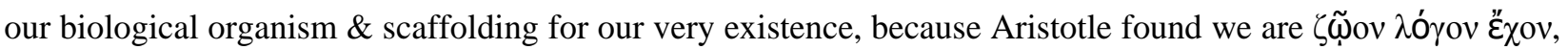
the thinking animal, and our analytic geometry teacher, René Descartes, also taught us je pense donc je suis, we exist by thinking.

Evolving an organ to store \& process facts became imperative, a central nervous system, crowned by a brain. We were enabled thereby to acquire knowledge. In complete neuro-anatomic realization of Kant's two senses of his transcendental aesthetics, we can discern two types of human sensory-mental capacities: A spatial geometric, primarily visual image $\&$ tactile sense in the right brain, and a temporal logical sequential sense in the left brain. Darwinian evolution of our early bilaterian animal ancestors led to the creation of our asymmetric bilateral brain, with a profound division of labor between hemispheres. ${ }^{3}$ Such a biological IT apparatus is our central information processing unit. In humans there are 80 billion neurons in the brain, 40 billion in the cortex, the other half in the cerebellum for fine motor control. At least 25 billion cortical neurons are of the giant pyramidal type, perhaps amounting to so many Apple Macbook Air notebook computers in their processing power.

\footnotetext{
${ }^{3}$ Asymmetry in the brain is common among vertebrates, even invertebrate bees (Corballis, 2009; Neubauer et al., 2020; Petrazzini et al., 2020; Rogers \& Vallortigara, 2015).
} 
Actually the view today seems to be that the brain drives adaptation of the organism, evolving itself and a body for itself to go along with its preferred modus operandi.

We humans are opportunistic animals and for us to survive \& thrive, we require to have as much information available to us as possible, concerning the condition \& circumstances of the environment, including food, shelter, other members of the species, predators, far \& wide, past history, \& future anticipation. Apparently, the evolutionary step of neural encoding was achieved on the unicellular level, during a hypothetical ciliate radiation that must have preceded the Cambrian age, perhaps in the Ediacaran or more likely even earlier during the Neoproterozoic.

This tentative conjecture is based on unicellular Paramecium, the Slipper Animal. Familiar from biology classes, it is found in almost any drop of water from a puddle in your backyard. Paramecium is one among ciliates (phylum Ciliophora), similar to a one-celled ancestor. As I watch it scurrying about under the microscope, it is searching for food particles, and it certainly seems to know somewhat what it is doing.

Paramecium, being a typical representative of that protozoan phylum is remarkable for each unicellular individual being its own nerve cell. Apparently, its ciliate macronucleus, which contains about $80 \%$ of the genome at 500-fold ploidy, serves as the animalcule's cerebrelle, its brainlike organelle. It might be said that this protist is at once its own nerve cell. With its macronucleus, here I seem to identify the original nervous apparatus, and the precursor of multicellular neuronal systems.

Ciliates are remarkably diverse in the details of how the macronucleus or cerebrelle is formed and disintegrates during reproduction which can proceed two ways, by mitosis or by sexual reproduction with conjugation and diploid zygote formation, with subsequent mioitic cell divisions back to the normal haploid individuals.

What passes through Plato's metaphysical gap is strictly superficial \&/or surficial and excludes quantum foam that covers \& surrounds reality. A certain kind of superficiality in our casual acquaintance with the universe has always been apparent. Socrates, in the early Platonic dialogues, makes it his unpleasant habit, so Athenians came to learn, to annoy and antagonize everybody, unhesitatingly revealing they didn't know much about of what subjects they were talking about. As a result, we can proclaim Science Meets Philosophy...!! It's all just a question of one or more neural mechanisms.

As readers probably should be informed, my goal is a complete transformation of philosophy to become fully holistic, fully integrated with cognitive science, physical science and all science. We now know enough about the brain, so philosophy should always be mindful of its analog form of neural mechanisms \& their throughput.

\section{Common Sense Judgment Power Resides in the Bilateral Interior Cosmos}

Synopsis: Human judgment power, Kant's Urtheilskraft, our holistic common sense, is made possible by the bilateral interior cosmos. We judge truth, the nature of things and the course of events by fitting all into the interior cosmos, similar to Quine's Web of Belief.

We form a whole system, a veritable bilateral interior cosmos, a kind of world model, in a language capable of expressing what may lie beyond the metaphysical gap.

The ontological status of environmental phenomena ${ }^{4}$ was the subject of prior work (Burchard, 2005,

\footnotetext{
${ }^{4}$ Unlike Kant's mental entities, neurally coded in the right brain.
} 
2011), where we identified them as prelinguistic structures or forms. ${ }^{5}$

Prelinguistic structures occur in the environment, typically those that are dealt with in routine daily traffic by public \& private persons, or can be captured in a scientist's field notebook. This will cover especially all matter of scientific investigations or experimental setup. It may be inferred that coarse-grained data suffice for most purposes. In reality we usually have only limited access to fine detail, when reporting or recording prelinguistic structures, unless a great investment can be made of time \& resources, as animal life is opportunistic.

As an example take a rock formation on a highway near you, laid bare by a road cut, as my phenomenon. On the noumenal side a geologist's reading of the rock layers, held externally as his field notes, a verbal record which he internalized prior to putting it on paper, using alphabet and numerals. In case of a hilly landscape being the natural terminus of the metaphysical gap, on its human end I may read a contour map of the hills as a more general form of image language.

I can overcome the gap by my judgment power founded in the noumenal cosmos, a world-model internally held in the brain. The contrast could not be greater.

Although the cosmos is meant to describe reality, its realism will exclude fine detail, available in conscious presence only on recall, perhaps requiring a Google-like search. Resemblance of the bilateral cosmos with the environment is of poor fidelity \& restricteded to prelinguistic structures. Impressions from the momentary scene in the environment, radiated by phenomena making up the scene enter the sensory neurons. Signals originating from prelinguistic structures in the environment can cross the metaphysical gap \& thereby turn into sense data.

This conversion is done in, \& the sense data take shape through, the synthesizing action of neural receptors acting as digitizers, subject to massive feedback from prefrontal lobe centers in the cerebral cortex. More on this below.

Sense data then travel along afferent nerve fibers ordered somewhat by geometry of origin but in fairly chaotic fashion, identified in preliminary fashion, \& arrive in our prefrontal brain to be given their place in the cosmos, fitted into the existing model.

This way, a needed bridge can be formed that is able to cross over the metaphysical gap as it stretches between reality \& our human experience.

The cosmos is regularly updated with novel environmental phenomena, as sense data are getting integrated into our memory banks. This was recognized early by Helmholtz (1860s).

The interior cosmos is part of the Default Mode Network (DMN), discovered by Raichle \& coworkers at WUSTL (Raichle et al., 2001). The DMN consists of the interior cosmos as its principal part, located in the prefrontal lobe structure, the central command post headquarters of the brain, serviced by the ventral stream of the sensory part of the looped brain, while important toolbox functions are located in parietal cortex receiving the dorsal stream. The motor cortex carries the control data stream from the BA10.

As found in recent decades, we make our interior cosmos largely as a free creation, using "top-down" processing.

The cognitive learning chores pile up on on our mental desktops, leaving it up to that network to knit together a Quinean Web of Belief (Quine \& Ullian, 1978), hopefully well-organized, simplified, prettified,

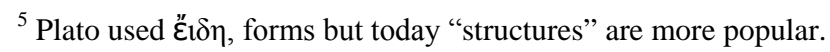


garnished beyond belief with cosmetics of our own creation out of the ugly chaotic swamp in which we find ourselves at least half the time of our lives.

Massive feedback is sent to lower centers helping with the ID.

The main points are that we need to be realistic. Our interior cosmos necessarily is something of a free creation, a sketch of reality but not a exact mirror image, which was Rorty's point, that he could understand only halfway. For a long time, cognitive scientists believed the brain was very good at analyzing sense data, such things like corner or line detection, etc. This is now called Bottom-UP (BU) processing. It is hopelessly inefficient \& much too slow. No animal could survive if it depended on BU. Instead it has been recognized in recent decades that we make our interior cosmos largely as a free creation, using Top-Down (TD) processing. There still are plenty of hold-outs, if you follow the literature, who think in terms of BU.

A lack of scientific approach to the question what am I has been a concomitant of a lack of esteem for my natural endowments with the key resource of Urteilskraft, judgment power, through reasoned, holistic understanding in form of a noumenal cosmos of myself, in this my world.

This bilateral cosmos is responsible for our common sense judgment power, that we depend on for being able to lead a good \& benign life. It is by $\&$ in the noumenal, left-brain cosmos, upon the basis of which we can form judgment for the actions of the present and even perform future anticipation.

Primacy of sound judgment (G. guter Rat) in human affairs is acknowledged as being the chief virtue of all men \& women in their daily action, yet all too often we find ourselves at a loss of what to do (G. ratlos).

There is common sense, our innate ability to judge all things, but in need of maturation, as illustrated by the silly rioters \& looters of a very young age who moreover have been taught utilitarianism, a left wing philosophy, a branch of behaviorism, I think.

From the interior cosmos, realized in both cerebral hemispheres, I derive the power of judgment, which is the chief purpose \& function of the cosmos, not perfect, but I have the capacity for charting a course of action of my own choosing.

\section{Our Free-Floating Double Ego}

Synopsis: Proud humans, being subjected to the evolutionary necessities of cerebral bilateral asymmetry, we must concede being possessed of two Egos, one in each hemisphere: Public Ego in the right brain, but private Ego in the left brain.

A human being has two egos, one in each cerebral hemisphere, giving us conscious existence. The bilateral double ego is maintained in the prefrontal lobes, originating as a $40 \mathrm{~Hz}$ gamma rhythm oscillation, services mysteriously performed by the bilateral linguistic brain in the 200 million prefrontal lobe neurons of Brodmann Area BA10, left \& right.

Korbinian Brodmann studied the different parts of the brain, classifying each according to neuro-architectonic features. He died when he accidentally cut his finger in the lab, before WWI, no antibiotics yet available.

The brain's two polarfront lobes are placed just above the eye brows, exercising Immanuel Kant's Oneness Function. For Kant, the source of experience was the manifold of sense-data in the imagination subject to the Oneness Function (G. Funktion der Einheit) in apperception, the source of his famous synthesis. Each human being exercises a function of unity, leading to questions of liberty. Ultimately, Nature herself may be the Parmenidian One that provides all unity of experience (Kant, 1781, 1787, A110-11, 121). 
Included in our conscious existence is an internal world model, the organized record of our interconnected, or general, experience, integrating sense data from across the metaphysical gap with memory associations, under constant analytical revision forming a bilateral interior cosmos:

Left brain: time, noumenal cosmos, imaginary interior castle, \& the complexity of our eternal existence.

Right brain: space, phenomenal cosmos, observed environment, \& the hardship of our instantaneous earthly life.

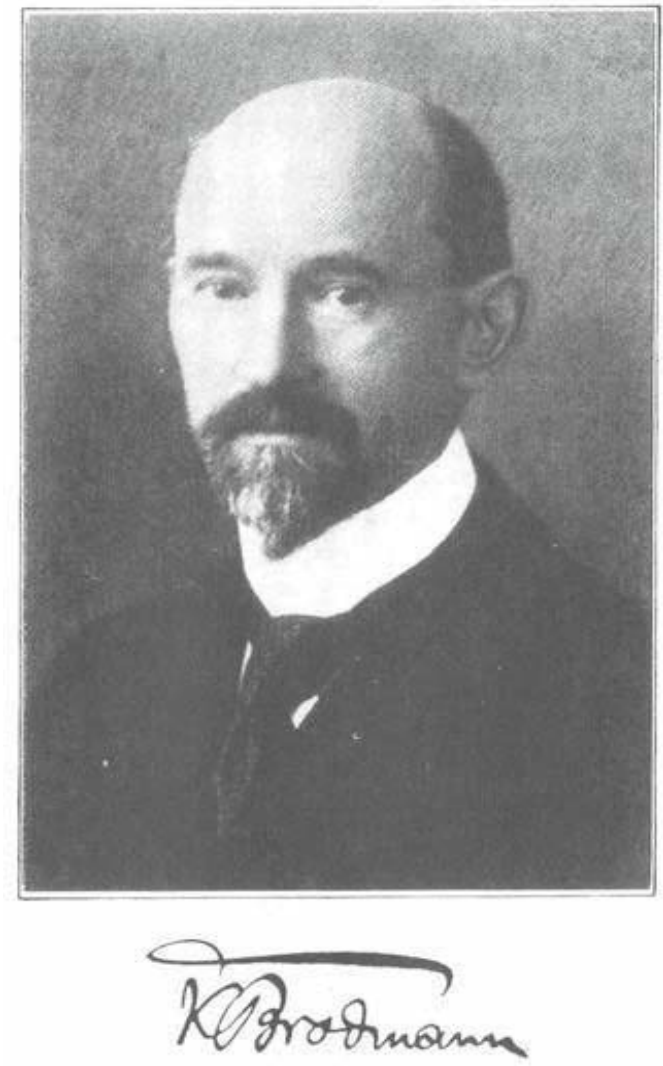

Figure 3. Korbinian Brodmann.

At any given time, I am reflecting on the current status of myself as well as of my external environment, fitting all inside my orderly cosmos as faithfully as possible.

Cautionary remark, there are 200 million neurons in BA10 alone, very dense arborization of the dendrites, how do they make Unity?

In complex environmental \& societal situations, so common in our daily lives, our BA10 can help us to keep track of our own actions, those of others \& extraneous events simultaneously in our outer sense right brain, as I think we all know from our own lives, while watching over our plans, intentions for ourselves \& duly considering all options, in the left hemisphere. We require our conscious free will decision making \& always must do the best we can.

The left brain -is for our innermost thoughts, our private world, our plans for the day, Immanuel Kant's noumena, mental entities, organized sequentially in time. The other half-in the right brain-is for the external environment, whatever goes on in the public world, Kant's phenomena in geometric space. Right brain Ego is public, an opportunist that keeps track of the world around us, any threats or goodies that might come into view 
quite suddenly.

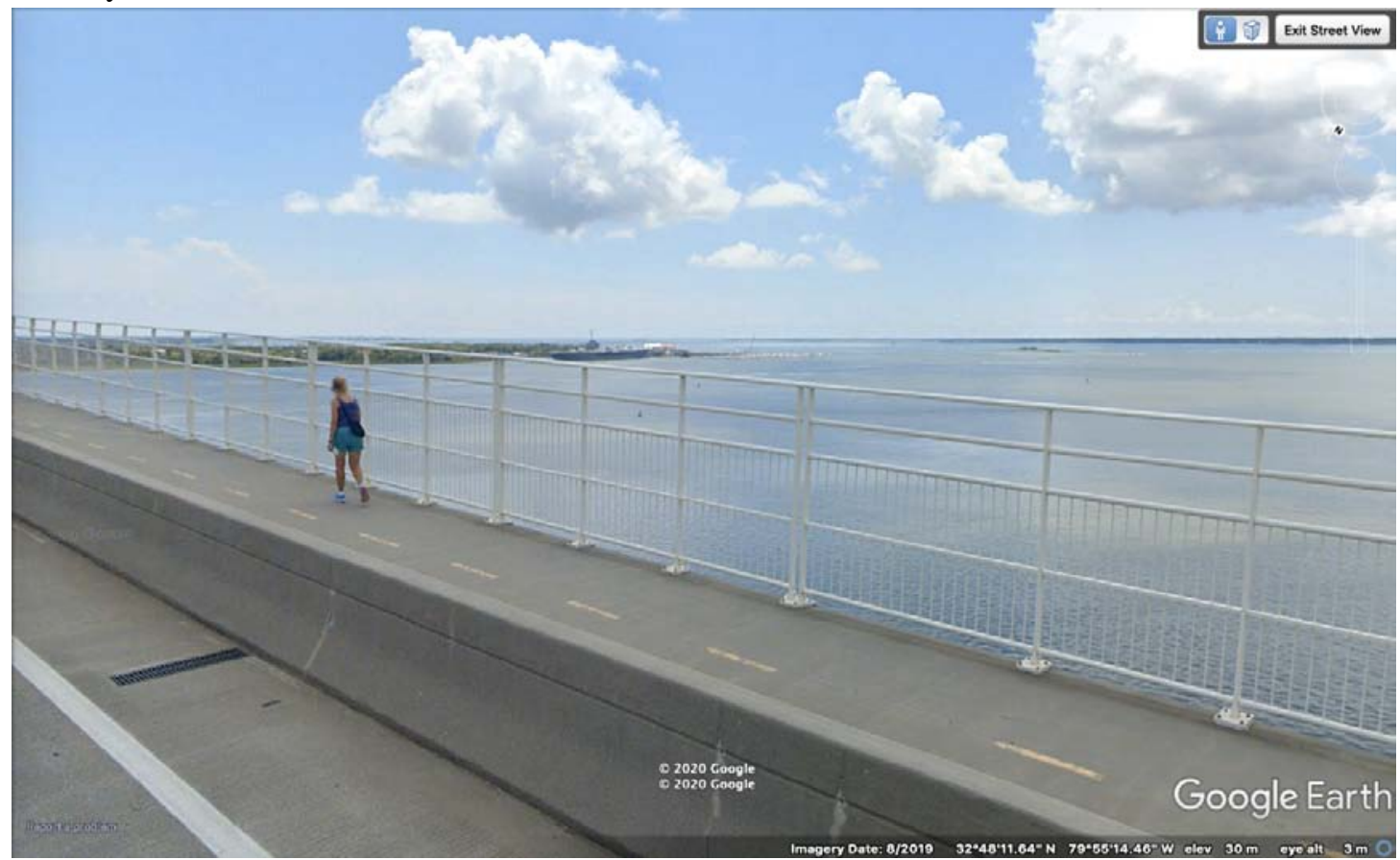

Figure 4. An anonymous young woman walking her personal bridge to tomorrow. Her eyes are on the walk way, not the magnificent vista of the bay, or the museum aircraft carrier in the distance. Inwardly, she is ordering her noumenal cosmos, her left brain refuge of Saint Teresa’s interior castle. Google Earth street level image.

Private Ego lives in the left brain fully occupied with its own ideas \& plans, although being kept well-informed about reality through the corpus callosum. By exercising Kant's oneness function, we synthesize \& organize sense data, a panoply of records from our interconnected individual \& tribal experiences.

Our existence rolls off like a movie, one $25 \mathrm{~ms}$ frame at a time, fourty frames a second on average, under normal conditions. It all is just the operation of a neural mechanism formed in circuitry of our bilateral, linguistic-computational brain. The overarching principle in this work is what goes on in the convolutions of the brain, not logic or authority. The aim of this work is to get people to be mindful of their interior cosmos. I use interior in deference to Saint Teresa of Avila but internal may be suitable as well. That human lives ek-sist in purely momentary instants is a great consolation for all of us, as we are facing an inevitable death ending what seems so precious, the sun shining, a friendly smile. It implies that our souls should be counted as eternal, although dependent on a blood stream carrying fuel \& oxygen. The question is: How do we respond to, or at least recognize, that conscious life is always "in the now," i.e., instantaneous?

It turns out, Buddhists believe there is only one instant, while past \& future are mere illusions. The difficulty of explaining change is traditionally considered to go with this Parmenidian perspective. Prayer and meditation should be practiced constantly.

Strangely, the instant, instantaneity, in human life so far remains unexplored \& ignored \& no psychologist or philosopher appears to think, follow or examine its nature. Instead a widespread belief in mental states has spread itself like a virus, contradicting the discovery of a gamma-rhythm "movie in the brain” (Damasio, 1994; Parvizi \& Damasio, 2001).

Any conscious state would be short-lived, of at most 25 ms duration. An inherent delay of the conscious 
"now" by about 300 ms is noted by Damasio.

This entirely unfounded belief in mental states has severely hindered philosophers \& distorted their published theories, being misled, \& failing in their attempts to understand consciousness when they ignored its most striking characteristic.

Albert Einstein on his deathbed asked Rudolf Carnap about this puzzling condition in a conversation about the "Now," saying nothing like it existed in physics. Einstein said the now is not physics. He does not say it's an illusion. He wants Carnap, who is a famous logician, explain what the instant now is, realizing on his death bed that it is all, is everything we have (Weizsaecker, 1992). ${ }^{6}$

Some may object to consciousness being instantaneous, because we always can access the full splendor of our inner left-brain cosmos— \& right brain — but when we do so, this will quickly change the momentary scene and in the instant we think of a childhood event, say, we have entered into the next 25 ms time interval and into a new top movie frame (Burchard, 2011).

The 200 million neurons of BA10 have global access to all available data as represented in the combined noumenal \& phenomenal interior cosmos, \& apply massive feedback to identify environmental conditions rapidly, achieving motor cortex commands to within 300 ms of events.

The global access also gives conscious presence of the individual to itself, all that is present in the interior cosmos, for total freedom of actions. In any situation, we can be aware of external events \& internal designs. This simultaneous overview is needed in critical survival situations.

We can survive adverse conditions due to the left brain private inner self...

Finally coming to the main points, we ever need to be watchful to keep our bilateral interior cosmos in good shape or our well-being comes under threat. This is detailed in the early 3-page version of this essay, included below. ${ }^{7}$

\section{Psychosomatic Health \& Wellbeing}

Synopsis: Our physical wellbeing depends on a healthy interior cosmos.

Our lives, health \& well-being depend on us keeping our interior cosmos in good order. This used to be seen as saving one's precious soul from perdition. While we endeavour to keep our phenomenal cosmos neat \& orderly by protecting the environment from harm, our noumenal cosmos to be livable requires us to engage in ethical conduct. Half of all our troubles go into the interior cosmos, half are our own doing. We must guard our inner world and keep it in good order, a cosmos, or we may fall ill.

Criminals are known to atrophy their brains' frontal lobes, saying to themselves: "I know it is wrong but I do it anyway." The 200 million neurons of the prefrontal lobe then kill those neurons that tell the crook about right $\&$ wrong, seeing they are not needed.

Our doctors, on whom we depend so frequently from beginning to end of our brief \& often broken existences, our physicians have had to search among the heterogeneous influences on our frail bodies for the main root causes of the diseases that we bring to them, being well aware of Plato's metaphysical gap.

A confusing tangle of causes and causatory pathways needs to be pried apart to see what is the nature of the disease.

\footnotetext{
${ }^{6}$ Zeit und Wissen, pp. 81-82.

${ }^{7}$ Psychosomatic Health \& Wellbeing (Burchard, 2020b).
} 
An excellent article in Wikipedia describes the multifarious ways in which a person can get to be sick.

But somehow, a prevalence of psychosomatic causation of many diseases requires to look into the metaphysical gap so deeply that it may have made MDs uncomfortable and the whole idea is currently being dismissed in favor of behavioral-social disorders (Rorty, 1979).

Still, even nowadays, an acknowledged psychosomatic influence is stress as in peptic ulcers, but for cancer although there is a debate, the evidence is considered weak. New evidence of a sympathetic immune response has become available (Nevin et al., 2020).

Contrariwise, we find examples for leukemia in cases, that could be adduced, to be caused by stress, a generic term which includes many different forms of psychic loads so heavy that the point is reached of breaking a person's ability to go on living.

Both Pope John Paul II \& the Nazi dictator Adolf Hitler suffered physical injuries from failed assassination attempts \& both subsequently developed Parkinson's disease.

In the case to JPII, during papal mass in St Peter's cathedral, the pope's fearful gaze toward the camera became painfully apparent. Vatican governance acted irresponsibly by permitting the pope's return to his official duties without imposing a lengthy period of recovery in his chambers and in the Vatican gardens. There were several earlier popes who could not serve for periods of time and were kept out of public view. Such constant fear as JPII seems to have been subject to is an extreme form of stress that can damage the central and peripheral nervous systems, with noxious signals sent from the psyche to the soma ultimately leading to Parkinson's.

In the case of leukemia, brain-bone marrow connections were discovered by University of Florida scientists, that provide direct sympathetic neuronal input to the bone marrow (Santisteban, 2013). Some children lose all hope for a normal childhood \& contract leukemia when their frantic parents find themselves in a career make or break struggle. Autoimmune diseases are another class of illnesses where psychosomatic etiology seems indicated.

Flannery O'Connor is a distinguished example of this connection. Her nightmarish tales, considered the very best of short stories, are simply her experiencing her own nightmarish life, put out into the open in metaphorical form. She experienced her own existence as a horror story and in so doing, not finding a salvific way out, her frail body got the message and we lost her at much too young an age.

Similarly in senile dementia, but here not somatic, but psychopsychotic (a neologism), a brain destroys itself when the whole life of the person amounted to a great frustration \& disappointment, as demonstrated in identical twin cases. A 2nd cousin suffered this way, being a highly creative architect, but never elevated into upper management of a large architecture firm \& consequently he never saw his own ideas realized in any actual structures. His daughter published a book describing his demise (Tietjen, 2015).

Recent medical research appears to have revealed biochemistry details that offer hope for a cure, although perhaps unofficially (Taylor, Swerdlow, \& Sullivan, 2019). Neurons discard or deactivate the insulin receptors in their cell walls if inactive during a hopeless life in an unsuccessful career. Without insulin binding to the neuron, glucose metabolism needed for the cell's energy supply shuts down.

However, energy to such neurons may be resupplied through an alternate so-called ketogenic metabolic pathway by ingestion of medium chain triglycerides (MCT), naturally occurring in plant \& animal fats, e.g., coconut oil, \& available in supermarkets. A few teaspoons a day can be mixed into food or coffee for a 
ketogenic diet, widely recommended for anybody over 65 . While the diet keeps alive failing neurons, the basic underlying issue of a ruined lifetime career remains unresolved.

Corresponding to the alternate MCT energy supply, to achieve an actual cure, dementia victims also must seek an alternate life plan, perhaps take up painting or experience a religious conversion.

\section{Faith \& Piety}

Synopsis: The imperfections of a finite albeit adaptable computing system, which our brain appears to be, require us to be open to the infinite beyond, its recondite wisdom, divinity to help us out in our need.

In the left brain private ego, we are guarded by faith in divine mercy. We receive the Holy Ghost directly in Saint Teresa's castillo interior. His angel guides us to choose the best course of action. The Holy Ghost was familiar to people in the time of Jesus, who mentions Him. Not a Christian doctrine at all, but due to Zarathustra (Zoroaster).

We can survive in the most adverse conditions. We love the Sermon on the Mount, the Beatitudes: "Blessed are the downtrodden, theirs is the Kingdom of Heaven." This unorthodox translation is based on a parallel in Isaiah, that Jesus likely had in mind, when pronouncing his 1st beatitude.

Blessed are the peace keepers. Usually translated "peace makers," but that is not what Jesus would have said. You make peace with the sword, but you keep peace by being gentle.

Blessed are they who hunger and thirst for righteousness. This is what we know the civil rights movement was based on, not riots.

Blessed are the merciful. Equal justice for all is a demand that seems to be based on mercy, opposite to dominance \& supremacy.

Life is tough, but late in life we can discover mercy. Americans understand mercy as fairness, a highly regarded virtue. There is a mercy movement in the Catholic Church. Maybe the unruly \& unholy mob in the streets is just confused? They do not know the gospel on which American democracy is founded, unlike the Athenian. We must try \& explain.

The nonsense of "Pascal's Wager:" We need to be in a daily personal relationship with the Creator of Eternity for to save our precious souls from perdition. So a person of faith would not usually engage in such a consideration. Yet such is taught to our young people in their general education classes.

Reality is different for everybody (my ex-wife used to assure me) but in divinely pre-established harmony according to Leibniz (caution, the city is spelt Leibnitz). The conversation sickness can be healed fortunately by common sense, matured through experience, deepened by suffering, all of which are individual traits, not social.

Society only serves to water down the creations of individuals. This is where religion comes in, as the hope for Providence, as they used to call him (her), our divine parent, holy trinity, a most ingeniously formulated model for the incomprehensible...

\section{Summary and Conclusions}

According to Plato's Cave Allegory, we can access phenomena in our world only indirectly.

However, by means of our brain, its powerful cerebral cortex, we are able to synthesize and compose a simplified orderly model of the universe, an interior cosmos.

Our performance in life depends on a well-maintained cosmos. Signals from the brain are sent to every 
organ, the entire somatic part of our existence, reflecting aspects of our perception of reality, by virtue of the interior cosmos.

Any malformation of the cosmos is liable to have a deleterious influence on organs, we fall ill. Our upbringing, education and social environment are prime sources of the quality of our interior cosmos. Good care by parents as well as teachers \& excellence of the environment are required for a young person to enter into an adult world with a viable cosmos.

Finally, remember we are living in a dream world. Only surficial or superficial features of reality make it through the metaphysical gap, so we each have to dream up an interior cosmos, by means of the Kantian Oneness Function, gluing together the items we care for. We live a public Ego in the right brain, I am trying to learn to be a good American after a childhood too horrible to tell, yet with nice memories. But you are entitled to absolute privacy in your left hemisphere, said to be dominant. Don't forget to keep it clean, and that your Cartesian existence requires you to link up with the Divinity ${ }^{8}$ that is available to all because the Holy Ghost keeps knocking at the door, asking to be invited in. Saints Peter \& Paul go so far as to advise constant prayer. Because our existence is momentary, a Cartesian thought, we should not be surprised that a Ghost is there to help us. We just were misled because of a faulty materialistic upbringing in most cases. Constant prayer helps you out with avoiding bad decisions and discovering a good way out of trouble.

\section{References}

Bird, C. M., Capponi, C., King, J. A., Doeller, C. F., \& Burgess, N. (2010). Establishing the boundaries: The hippocampal contribution to imagining scenes. The Journal of Neuroscience, 30, 11688-11695. https://dx.doi.org/10.1523/jneurosci.0723-10.2010

Brook, A. (2006). Kant: A unified representational base for all consciousness. In U. Kriegel and K. Williford (Eds.), Self-representational approaches to consciousness (pp. 89-110). Cambridge, MA: MIT Press.

Burchard, H. G. W. (2005). Symbolic languages and natural structures. Foundations of Science, 10, $153-245$. https://dx.doi.org/10.1007/s10699-004-3068-9

Burchard, H. G. W. (2011). The role of conscious attention in perception. Foundations of Science, 16, 67-99. https://dx.doi.org/10.1007/s10699-010-9201-z

Burchard, H. G. W. (2014). The cognitive gap, neural darwinism \& linguistic dualism. Open Journal of Philosophy, 4, $244-264$. Published Online August 2014. https://doi.org/10.4236/Ojpp.2014.43032

Burchard, H. G. W. (2016). Philosophy and science, the Darwinian-evolved computational brain, a non-recursive super-turing machine \& the inner-world-producing organ. Open Journal of Philosophy, 6, 13-28. Published Online February 2016. https://doi.org/10.4236/ojpp.2016.61002

Burchard, H. G. W. (2019). Georg Cantor's ordinals, absolute infinity \& transparent proof of the well-ordering theorem. Philosophy Study, 9(8), 435-444. https://doi.org/10.17265/2159-5313/2019.08.001

Burchard, H. G. W. (2020a). The neural basis of human conscious existence. Philosophy Study, 10(1), pp. 44-93. https://doi.org/10.17265/2159-5313/2020.01.006

Burchard, H. G. W. (2020b). Undiagnosed medical causation—Psychosomatic etiology. Philosophy Study, 10(4), $229-232$. https://doi.org/10.17265/2159-5313/2020.04.001

Corballis, M. C. (2009). The evolution and genetics of cerebral asymmetry. Philosophical Transactions of the Royal Society B: Biological Sciences, 364(1519), 867-879. https://doi.org/10.1098/rstb.2008.0232

Damasio, A. R. (1994). Descartes' error: Emotion, reason, and the human brain. New York: Putnam.

Frisk, V., \& Milner, B. (1990). The role of the left hippocampal region in the acquisition and retention of story content. Neuropsychologia, 28, 349-359. http://www.sciencedirect.com/science/journal/00283932/28/4

Iglói, K., Doeller, C. F., Berthoz, A., Rondi-Reig, L., \& Burgess, N. (2010). Lateralized human hippocampal activity predicts navigation based on sequence or place memory. Proceedings of the National Academy of Sciences of the United States of

\footnotetext{
${ }^{8}$ In line with this essay, this is an abstract neuronal entity. However, it also should stand for the ground of all Being.
} 
America, 107, 14466-14471. https://dx.doi.org/10.1073/pnas.1004243107

Kant, I. (1781 A, 1787 B). Critique of pure reason. English translation: Marcus Weigelt (2008), based upon translation by F. Max Müller (1881). Penguin Modern Classics.

Kant, I. (1790). Critique of the power of judgment. The Cambridge Edition of the Works of Immanuel Kant. Cambridge University Press.

Milner, B. (1971). Interhemispheric differences in the localization of psychological processes in man. British Medical Bulletin, 27, 272-277. http://bmb.oxfordjournals.org/content/by/year/1971

Neubauer, S., Gunz, Ph., Scott, N. A., Hublin, J.-J., \& Mitteroecker, Ph. (2020). Evolution of brain lateralization: A shared hominid pattern of endocranial asymmetry is much more variable in humans than in great apes. Science Advances, 6(7), eaax9935. https://doi.org/10.1126/sciadv.aax9935

Nevin, J. T., Moussa, M., Corwin, W. L., Mandoiu, I. I., \& Srivastava, P. K. (2020). Sympathetic nervous tone limits the development of myeloid-derived suppressor cells. Science Immunology, 5(51), eaay9368. https://doi.org/10.1126/sciimmunol.aay9368

Parvizi, J., \& Damasio, A. R. (2001). Consciousness and the brainstem. Cognition, 79, 135-159. https://doi.org/10.1016/s0010-0277(00)00127-x

Petrazzini, M. E. M., Sovrano, V. A., Vallortigara, G., \& Messina, A. (2020). Brain and behavioral asymmetry: A lesson from fish. Frontiers in Neuroanatomy, 14, 11. https://doi.org/10.3389/fnana.2020.00011

Plato. (375 BC). The Republic, Book VII. The Dialogues of Plato, translated into English with Analyses and Introductions, B. Jowett, translator. Vol. 3, 3rd ed. Oxford University Press (1892).

Quine, W. V. O., \& Ullian, J. S. (1978). The web of belief (2nd ed.). New York: McGraw-Hill Humanities/Social Sciences/Languages.

Raichle, M. E., MacLeod, A. M., Snyder, A. Z., Powers, W. J., Gusnard, D. A., \& Shulman, G. L. (2001). A default mode of brain function. Proc Natl Acad Sci, 98, 676-682. https://doi.org/10.1073/pnas.98.2.676

Rogers, L. J., \& Vallortigara, G. (2015). When and why did brains break symmetry? Symmetry, 7(4), 2181-2194. https://doi.org/10.3390/sym7042181

Rorty, R. (1979). Philosophy and the mirror of Nature. Princeton, NJ: Princeton University Press.

Santisteban, M. M., Zubcevic, J., Baekey, D. M. et al. (2013). Dysfunctional brain-bone marrow communication: A paradigm shift in the pathophysiology of hypertension. Curr Hypertens Rep, 15, 377-389. https://doi.org/10.1007/s11906-013-0361-4

Smith, M. L., \& Milner, B. (1989). Right hippocampal impairment in the recall of spatial location: Encoding deficit or rapid forgetting? Neuropsychologia, 27, 1-81. http://www.sciencedirect.com/science/journal/00283932/28/4

Taylor, M. K., Swerdlow, R. H., \& Sullivan, D. K. (2019). Dietary neuroketotherapeutics for Alzheimer's disease: An evidence update and the potential role for diet quality. Nutrients, 11(8), 1910. https://doi.org/10.3390/nu11081910

Teresa of Avila, St. (1577). Castillo interior, or Las moradas.

Tietjen, B. (2015). Unter Tränen gelacht. Mein Vater, die Demenz und ich. Piper Verlag, München. ISBN 978-3-492-05642-7.

Weizsaecker, C. F. von. (1992). Zeit und Wissen. Munich: Hanser Verlag. ISBN 3-446- 16367-0. 